\title{
Chapter 14 \\ Seeking Retrospective Approval \\ for a Study in Resource-Constrained \\ Liberia
}

\author{
Jemee K. Tegli
}

\begin{abstract}
The increase in the volume of health-related research in Africa has not everywhere been accompanied by improvements in research oversight systems related to biomedical and health services research, including the strengthening of institutional review boards (IRBs) and national regulatory oversight institutions. Critical to such oversight are not only competencies in ethics for the review of clinical trials, but also competencies in diverse research methods, statistical analyses and project implementation. In Liberia, there are recognized weaknesses in the existing infrastructure and capacity to regulate and monitor clinical research based on ethical institutional regulations and guidance for the protection of human research participants. During the height of the Ebola virus disease (EVD) surge in Liberia in 2014, there was a fragile national regulatory framework to oversee research. Some researchers took undue advantage of this gap to conduct unethical research.
\end{abstract}

Keywords Ebola Virus Disease $\cdot$ Liberia $\cdot$ Emergency research

Retrospective approval $\cdot$ Ethics committee $\cdot$ Institutional review board

This case study is about an attempt to seek ethics approval after the study had already been conducted. Trying to obtain retrospective approval of research undermines the legitimacy of an Institutional Review Board (IRB) and the research review process itself. If the level of risk that a research study on EVD survivors presents is only determined after its completion, then the participants would have already been exposed to harm and their autonomy compromised. The researcher in this case used the cover of "emergency research" to avoid the review process - although emergency

\author{
J. K. Tegli ( $\square)$ \\ PREVAIL OFFICE, 1st Floor, East Wing, JFK Medical Center, 21 Street, Sinkor, \\ Monrovia, Liberia \\ e-mail: tegli@ul-pireafrica.org \\ J. K. Tegli \\ UL-PIRE Africa Center, University of Liberia, Ground Floor, GD Bldg., \\ Monrovia 100010, Liberia \\ (C) The Author(s) 2018 \\ D. Schroeder et al. (eds.), Ethics Dumping, SpringerBriefs in Research \\ and Innovation Governance, https://doi.org/10.1007/978-3-319-64731-9_14
}


research regulations stipulate full disclosure of proposed research prior to implementation, and there are specified consenting processes (National Institute of Medicine (2002)).

\section{Area of Risk of Exploitation}

An investigator breached the Declaration of Helsinki and other global ethical guidelines by ignoring an ethical review oversight process that was fully functional in Liberia. The investigator was provided with information about the country's ethical review process at meetings of the Ebola Response Incident Management System, but chose to deploy the research team into targeted communities without ethical approval, collecting data through focus group discussions, key informant interviews and in-depth interviews. The data were analysed and submitted for presentation and/or publication at national and international meetings.

The entire data collection process, involving sensitive topics centred on Ebola-affected communities, was highly distressing. The consent process was conducted at the discretion of the researcher and the study team (Pollock, 2012). Providing so-called consent processes to participants in the frenzy of an epidemic can lead to misconceptions on their part. Risk mitigation measures were not fully assessed because guidance from an ethical institution was not explored or sought prior to the conduct of the study.

The fundamental pillar of respect for persons was also ignored. This should be the principle upon which each research participant makes an informed choice about whether or not to participate in the research, and thus accepts the potential risks and burdens of participation (Jasanoff, 1993). Thorough explanation to participants about the availability of the research ethics review board to address concerns regarding their rights or wellbeing, and providing contact information, are critical elements of the consent process. Whether consent is sought verbally or in writing, reference must be made to an ethics review board that reviewed and approved the research study. Ignoring one of the major pillars of ethical research - namely, ethics review - opens up a range of risks for exploitation (Martinson et al., 2005).

\section{Background}

Whatever the context, the need for the regulation of research is clear. In March 2014, the Ebola epidemic hit Liberia very hard. With Guinea and Sierra Leone also affected, the death toll in Liberia as of May 2016 stood at 4,810, with 10,678 infected. At the peak of the epidemic in October 2014, researchers and institutions were pouring into the country to conduct all forms of research, ranging from social science, anthropological and clinical studies. 
As a result of the health emergency, the ethical research institutions were overwhelmed with questions from many investigators and institutions seeking information about the application process. The ethical boards were approached by several potential investigators in and outside of Liberia for information and guidance about the review process in the country. In spite of the availability of this platform, some researchers proceeded to conduct their research studies in November 2014 without prior review and approval by the relevant IRB. They circumvented the process under the pretext of the emergency and collected data from human participants in an unethical manner.

A particular case came to light in December 2014, when the IRB denied a researcher employed by an international UN public health agency retrospective ethical approval. Such an attempt to obtain retrospective approval of research undermines the legitimacy of the IRB and the research review process itself. If the level of risk that a research study on Ebola virus disease (EVD) survivors presents is determined only after its completion, then the participants would have already been exposed to harm and their autonomy compromised. This researcher used the cover of "emergency research" to avoid the review process - although emergency research regulations stipulate full disclosure of proposed research prior to implementation, and there are specified consenting processes.

\section{Details of the Case}

In early December 2014, the University of Liberia-Pacific Institute for Research and Evaluation IRB received an application from a researcher working for an international UN public health agency seeking approval for medical anthropological research on survivors of EVD in Monrovia. The focus of the study was on gathering information on the economic well-being of EVD survivors in Liberia. The objective was to assess the psychosocial situation and the impact of stigma and discrimination on the lives of survivors.

The research, which took place at the height of the EVD surge from November to December 2014, involved several EVD-affected communities in urban and peri-urban Monrovia. Most were from semi-literate and illiterate populations and had already been traumatized by the surge in EVD deaths. This study therefore had the potential to inflict distress on these participants: for example, it is traumatizing for EVD survivors to recount their experiences or circumstances, because these involve very recent catastrophic events in their lives.

The IRB convened and expedited the review process, given the importance of conducting the proposed research in a timely manner during the EVD outbreak. At the time, the IRB was not aware that the research had already been completed when the application was submitted for review. The researcher had left Liberia and was not present at the meeting, but was represented by a less experienced Liberian research assistant (RA). 
During the IRB meeting, the RA was asked a question about the intended timetable for commencing the study. To the board's surprise, they were told that the data for the study had already been collected and analyzed. The role and responsibilities of this junior researcher in the implementation of the study were unclear and apparently minimal. The research team was only seeking approval from the IRB in order to disseminate the research results.

The IRB chair immediately called the meeting off and told the RA that the incident undermined best practices in the ethical conduct of health research. The RA was instructed to report the findings of the IRB to the principal investigator: namely that research had been conducted unethically, research review and approval regulations had been contravened, and the autonomy of the EVD survivors who were research participants had been breached.

\section{Reasons for IRB Decision and Conclusion}

A retrospective IRB approval of a research project - that is, after participants may already have been exposed to unnecessary harm or violation of their rights - would be unethical. Conducting a research study without IRB oversight violates both ethical principles and IRB procedures. In this context, the decision takes a stance on public policy that aims at increasing compliance with IRB requirements.

Without ethics approval, it is impossible to have the results of a study published in a reputable journal. One must assume that this is why the researcher tried to obtain retrospective approval. While the decision the IRB reached was emphatic, it was preceded by a short discussion on whether granting approval retrospectively, and thereby allowing publication of the research results, may contribute to the public good (Tansey et al., 2010). However, the IRB decided firmly in the negative, partly because the research had been undertaken on a highly vulnerable group of illiterate and uneducated Liberians who would have little knowledge of the consent process.

The Liberian IRB therefore made a clear decision to uphold the autonomy of both the IRB and the research participants by refusing to approve a study retrospectively.

\section{References}

Committee on Assessing Integrity in Research Environments (2002) Integrity in scientific research: creating an environment that promotes responsible conduct. The National Academies Press, Washington DC

Jasanoff S (1993) Innovation and integrity in biomedical research. Academic Medicine 68(9 Suppl):S91-S95

Martinson BC, Anderson MS, de Vries R (2005) Scientists behaving badly. Nature 435 (7043):737-738 
Pollock K (2012) Procedure versus process: ethical paradigms and the conduct of qualitative research. BMC Medical Ethics 13(1):25. doi: 10.1186/1472-6939-13-25

Tansey CM, Herridge MS, Heslegrave RJ, Lavery JV (2010) A framework for research ethics review during public emergencies. Canadian Medical Association Journal 182(14):1533-1537. doi: 10.1503/cmaj.090976

\section{Author Biography}

Jemee K. Tegli is Director of Operations for the Liberia-United States Clinical Research Program, Partnership for Research on Ebola Virus in Liberia. He previously worked for the University of Liberia-Pacific Institute for Research and Evaluation as Center Director. He serves as Coordinator of the UL-PIRE Institutional Review Board (IRB) and Member of the National Research Ethics Board (NREB) of the Ministry of Health. He is an international IRB Member of the Western Intuitional Review Board (WIRB)-Copernicus Group in Puyallup, Washington.

Open Access This chapter is licensed under the terms of the Creative Commons Attribution 4.0 International License (http://creativecommons.org/licenses/by/4.0/), which permits use, sharing, adaptation, distribution and reproduction in any medium or format, as long as you give appropriate credit to the original author(s) and the source, provide a link to the Creative Commons license and indicate if changes were made.

The images or other third party material in this chapter are included in the chapter's Creative Commons license, unless indicated otherwise in a credit line to the material. If material is not included in the chapter's Creative Commons license and your intended use is not permitted by statutory regulation or exceeds the permitted use, you will need to obtain permission directly from the copyright holder.

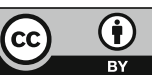

